\title{
Layers of Uranium Phosphate Nanorods and Nanoplates Encrusted on Fungus Cladosporium sp. Strain F1 Hyphae
}

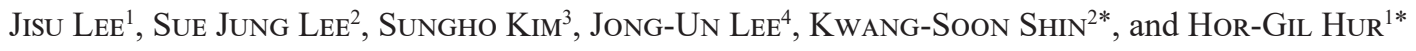 \\ ${ }^{1}$ School of Earth Sciences and Environmental Engineering, Gwangju Institute of Science and Technology, Gwangju 61005, \\ Republic of Korea; ${ }^{2}$ Department of Food Science and Biotechnology, Kyonggi University, 154-42, Gwanggyosan-ro, Youngtong- \\ gu, Suwon, Gyeonggi 16227, Republic of Korea; ${ }^{3}$ GIST Central Research Facilities, Gwanju Institute of Science and Technology, \\ Gwangju 61005, Republic of Korea; and ${ }^{4}$ Department of Energy and Resources Engineering, Chonnam National University, \\ Gwangju 61186, Republic of Korea
}

(Received May 7, 2021—Accepted September 21, 2021—Published online November 13, 2021)

The hyphae of Cladosporium sp. strain F1 (CFGR 2020-301-00084) were heavily encrusted with pre-synthesized uranium phosphate minerals under a wide range of $\mathrm{pH}$ conditions. SEM and TEM images showed that nanorods and nanoplates of uranium phosphate minerals at $\mathrm{pH} 4$ and 5 and at $\mathrm{pH} 6,7$, and 8, respectively, were tightly adsorbed along the hyphae of Cladosporium sp. strain F1, while only a few uranium phosphate minerals were observed on the hyphae of Aspergillus niger VKMF 1119. Based on the physical mobility and chemical stability of uranium phosphate minerals under in situ oxidizing environmental conditions, the application of Cladosporium $\mathrm{sp}$. strain $\mathrm{F} 1$ has potential as a novel strategy for the remediation of uranium contamination in sediments and aquifers under a wide range of $\mathrm{pH}$ conditions where larger amounts of phosphate are present in the environment.

Key words: uranium, nanoplate, fungus, biosorption, exopolysaccharides

The long-lived radioactive and chemically toxic element uranium acts as a mutagenic, carcinogenic, neurotoxic, and nephrotoxic chemical that affects the human kidneys, liver, lungs, and hematopoietic system, ultimately leading to death (Arzuaga et al., 2010; Hon et al., 2015). Although the ionizing radiation toxicity of uranium generally draws public concerns, uranium risks associated with chemical toxicity may be greater than those of radiotoxicity depending on its compound, composition, or enrichment grade (Rump et al., 2019). The chemical toxicity of uranium also depends on its oxidation state. Uranium predominantly exists in the environment in two oxidation states, tetravalent and hexavalent. Tetravalent uranium (U[IV]) is less soluble and mobile in the aqueous phase than hexavalent uranium (U[VI]) (Anderson, 1984). The toxicity of more soluble U(VI) is generally greater than that of less soluble U(IV) (Wufuer et al., 2017). By using differences in the solubility and mobility of the two oxidation states of uranium, various methods, including anaerobic bacterial respiration systems, have been proposed to remove U(VI) from the environment (Jiang et al., 2011; Li and Zhang, 2012; Jiang and Hur, 2013; Lee and Hur, 2014; Parth et al., 2014). However, it is important to

\footnotetext{
* Corresponding authors.

Hor-Gil Hur: E-mail: hghur@gist.ac.kr;

Tel: +82-062-715-2437; Fax: +82-062-715-2437.

Kwang-Soon Shin: E-mail: ksshin@kyonggi.ac.kr;

Tel: +82-031-249-9655; Fax: +82-031-249-9650.
}

Citation: Lee, J., Lee, S. J., Kim, S., Lee, J.-U., Shin, K.-S., and Hur, H.-G. (2021) Layers of Uranium Phosphate Nanorods and Nanoplates Encrusted on Fungus Cladosporium sp. Strain F1 Hyphae. Microbes Environ 36: ME21036.

https://doi.org/10.1264/jsme2.ME21036 note that reduced $\mathrm{U}(\mathrm{IV})$ may be easily re-oxidized to soluble U(VI) under oxidized field conditions (Casas et al., 1994; Abdelouas et al., 1999; Gu et al., 2005; Zhong et al., 2005; Zhou and Gu, 2005; Moon et al., 2009).

Therefore, a novel method to immobilize U(VI) species that considers physical mobility and chemical stability under oxidized conditions is needed. Uranium phosphate minerals may meet these conditions even in fluid-rich oxidizing environments. Phosphates play an important role in the immobilization of trace elements, including uranium, through secondary phosphate mineral precipitation in welldeveloped and fluid-rich weathering profiles (Banfield and Eggleton, 1989; Braun et al., 1998; Taunton et al., 2000; Mehta et al., 2013; Kanematsu et al., 2014). A number of uranium phosphate minerals have been observed in environments in which $\mathrm{U}(\mathrm{VI})$ and phosphate exist. Copper meta-torbernite $\left(\mathrm{Cu}\left[\mathrm{UO}_{2}\right]_{2}\left[\mathrm{PO}_{4}\right]_{2} \cdot 8 \mathrm{H}_{2} \mathrm{O}\right)$ and magnesium meta-autunite $\left(\mathrm{Mg}\left[\mathrm{UO}_{2}\right]_{2}\left[\mathrm{PO}_{4}\right]_{2} \cdot n \mathrm{H}_{2} \mathrm{O}\right)$ were detected near the Koongarra uranium deposit in Australia, and barium meta-autunite $\left(\mathrm{Ba}\left[\mathrm{UO}_{2}\right]_{2}\left[\mathrm{PO}_{4}\right]_{2} \cdot n \mathrm{H}_{2} \mathrm{O}\right)$ in the vicinity of the Coles Hill uranium deposit in Virginia, USA (Murakami et al., 1997; Jerden et al., 2003; Murakami et al., 2005; Jerden and Sinha, 2006). Due to the low solubility and high stability of uranium phosphate minerals under oxidizing conditions, the addition of phosphate to environments containing uranium has been suggested for its removal (Fanizza et al., 2013; Munasinghe et al., 2015; Baker et al., 2019). However, precipitated uranium phosphate minerals may cause other threats. Liu et al. (2015) reported that uranium phosphate particles entered normal rat hepatic BRL cells and induced apoptotic cell death. Therefore, methods with the ability to collect and remove stable uranium phosphate minerals from the environment are desired. 
Various organisms, including bacteria, fungi, algae, and plants, may be used as biomasses to adsorb heavy metals. Biosorption using a fungal biomass is considered to be more effective than that by other biomasses for a number of reasons including the high binding capacity associated with the large surface area of fungal hyphae, the ease of cultivating fungi on a large scale, and the use of inexpensive growth media (Dhankhar and Hooda, 2011). Therefore, many fungal biomasses, such as Aspergillus, Fusarium, Mucor, Penicillium, Rhizopus, Talaromyces, and Trichoderma, have been examined and identified as promising biosorbents to remove uranium in the environment (Gupta et al., 2018). Although Cladosporium is one of the most common fungi worldwide, the biosorption of uranium phosphate minerals by this fungal biomass has not yet been reported.

In the present study, we report the unusual adsorption phenomenon of the newly isolated fungus Cladosporium sp. strain F1 towards uranium phosphate minerals. The hyphal surface of strain F1 formed tight and extensive layers of nanorods and nanoplates made of uranium phosphate minerals, which may be used to collect and remove uranium in the form of stable uranium phosphate minerals from the environment. The role of fungal exopolysaccharides (EPSs) in uranium phosphate mineral binding was examined and characterized.

\section{Materials and Methods}

\section{Fungal strains, uranium preparation, and experiments conditions}

Cladosporium sp. strain F1 was isolated from contaminated solution containing U(VI) and phosphate in our laboratory, and deposited in the Center for Fungal Genetic Resources (Seoul, Korea) with the strain number CFGR 2020-301-00084. It was identified by its internal transcribed spacer (ITS) sequence, registered with the National Center for Biotechnology Information (Bethesda, MD, USA), and obtained the accession number of the ITS sequence of MT271897. Aspergillus niger VKMF 1119 was kindly provided by Dr. C. Cerniglia, the National Center for Toxicological Research (Jefferson, AR, USA). Both fungi were grown in potato dextrose broth (PDB) at $25^{\circ} \mathrm{C}$ with $150 \mathrm{rpm}$ for $7 \mathrm{~d}$ prior to experimental subculture.

To prepare uranium phosphate minerals, $1.97 \mathrm{mg}$ of uranyl nitrate was added to $50 \mathrm{~mL}$ of aqueous solution containing potassium dihydrogen phosphate $(0.14 \mathrm{mM})$ and disodium hydrogen phosphate $(0.21 \mathrm{mM})$. The solution $\mathrm{pH}$ was varied from $\mathrm{pH} 4$ to 8. After uranium phosphate minerals had been synthesized and precipitated in solution at room temperature for $24 \mathrm{~h}$, the fungal biomass was added. The fungus weight was $50 \mathrm{mg}$ of dry weight per $50 \mathrm{~mL}$ of solution. All biosorption experiments were performed at $25^{\circ} \mathrm{C}$ with shaking at $150 \mathrm{rpm}$ and conducted in duplicate.

After adsorbing uranium phosphate minerals to the hyphae of the two fungal biomasses for $12 \mathrm{~h}$, samples were filtered using a 5 - $\mu \mathrm{m}$ nylon net filter (Merck Millipore) to separate uranium phosphate minerals adsorbed on fungal hyphae and those remaining in solution. Filtrates, which contained the remaining uranium phosphate minerals, were centrifuged at $10,000 \times g$ for $10 \mathrm{~min}$. After centrifuging, uranium phosphate pellets were solubilized by acid treatments using $5 \mathrm{~mL}$ of concentrated nitric acid. Total uranium concentrations were assessed by inductively coupled plasma mass spectrometry (ICP-MS, 1100 \& 7500ce; Agilent Technologies). The kinetics of fungal biosorption toward uranium phosphate minerals were also examined by ICP-MS. Filtrates were collected after reacting for 1,3 , and $6 \mathrm{~h}$ at $\mathrm{pH} 7$ following the above process. Biomineralization experiments were performed with the two fungal strains in $10 \mathrm{~mL}$ MOPS buffer $(10 \mathrm{mM})$ at $25^{\circ} \mathrm{C}$ with shaking at $150 \mathrm{rpm}$. MOPS buffer containing sucrose at $50 \mathrm{mM}$, glycerophosphate at $2 \mathrm{mM}$, and uranyl nitrate at $0.4 \mathrm{mM}$ was adjusted to $\mathrm{pH} 6$. Experiments were conducted in duplicate.

\section{Identification of the isolated fungal strain}

The isolated fungal strain was identified using ITS sequence analyses. The ITS region was amplified by a polymerase chain reaction (PCR) using the following primers: ITS1 (5'-TCCGTAG GTGAACCTGCGG-3') and ITS4 (5'-TCCTCCGCTTATTGATAT GC-3'). PCR was performed using the following conditions: initial denaturation step at $95^{\circ} \mathrm{C}$ for $5 \mathrm{~min}$, followed by 30 cycles at $95^{\circ} \mathrm{C}$ for $30 \mathrm{~s}, 55^{\circ} \mathrm{C}$ for $120 \mathrm{~s}$, and $68^{\circ} \mathrm{C}$ for $90 \mathrm{~s}$, and a final extension step at $68^{\circ} \mathrm{C}$ for $10 \mathrm{~min}$. PCR products were purified using the Montage PCR Clean up kit (Merck Millipore). Purified PCR products were sequenced using Big Dye terminator cycle sequencing kit v.3.1 (Applied BioSystems) with the two primers above. Sequencing products were resolved on an Applied Biosystems model 3730XL automated DNA sequencing system (Applied BioSystems) at Macrogen. The elucidated sequences were aligned and a phylogenetic tree was constructed with the Clustal W program using the maximum likelihood method. The genetic distance of similar sequences was calculated using the MEGA 7 software program (Kumar et al., 2016).

\section{Isolation of EPSS}

Cladosporium sp. strain $\mathrm{F} 1$ and $A$. niger VKMF-1119 were grown in $\mathrm{PDB}$ at $25^{\circ} \mathrm{C}$ for $7 \mathrm{~d}$. Cultures were centrifuged at $10,000 \times g$ for $10 \mathrm{~min}$ and the supernatant was filtered using a $10-\mu \mathrm{m}$ nylon net filter (Merck Millipore). A four-fold volume of $95 \%(\mathrm{v} / \mathrm{v})$ ethanol was added and the mixture was kept at $4^{\circ} \mathrm{C}$ overnight. The resulting precipitates were recovered by centrifugation at $10,000 \times g$ for $10 \mathrm{~min}$ and desalted using Amicon Ultra-15 $10 \mathrm{~K}$ centrifugal filter devices (Merck Millipore). Samples were lyophilized and used in subsequent experiments.

\section{Structural characterization of EPSS}

In polysaccharide samples, total carbohydrate, uronic acid, 2-keto-3-deoxy-D-manno-octulosonic acid (KDO)-like materials, and protein contents were measured using the phenol-sulfuric acid method, $m$-hydroxybiphenyl method, modified thiobarbituric acid method, and Bradford method (Bio-Rad Laboratories), respectively (Blumenkrantz and Asboe-Hansen, 1973; Bradford, 1976; Karkhanis et al., 1978). The molecular weight (MW) profiles of polysaccharide samples were analyzed by high performance size-exclusion chromatography (HPSEC) using an Agilent 1260 Infinity LC system (Agilent Technologies) according to the method described by Lee et al. (2014). Sugar compositions elucidated using the 1-phenyl-3-methyl-5-pyrazolone (PMP) derivative method were analyzed at $30^{\circ} \mathrm{C}$ by high performance liquid chromatography (HPLC) (Shimadzu) equipped with a SPD-20A UV/VIS detector and Acclaim ${ }^{\mathrm{TM}} 120 \mathrm{C} 18$ column (Thermo Fisher Scientific) (Honda et al., 1989; Dai et al., 2010). The elution of PMP derivatives was performed using a mixture of phosphate buffer $(82 \%, 0.1 \mathrm{M}, \mathrm{pH} 6.7)$ and acetonitrile $(18 \%)$ at a flow rate of $1 \mathrm{~mL} \mathrm{~min} \mathrm{~m}^{-1}$. The UV absorbance of the eluate was monitored at $245 \mathrm{~nm}$.

A methylation analysis of glycosidic linkages within polysaccharides was performed using previously reported methods with minor modifications (Hakomori, 1964; Pettolino et al., 2012). In brief, dimethyl sulfoxide (DMSO) and methylsulfinyl carbanion with iodomethane were used to dissolve the polysaccharide fraction for the methylation of polysaccharides. Unmethylated parts were removed using a Sep-pak C18 cartridge (Waters), and the methylated sample was then hydrolyzed with $1 \mathrm{M}$ trifluoroacetic acid at $121^{\circ} \mathrm{C}$ for $90 \mathrm{~min}$. Sodium borodeuteride was used to reduce hydrolyzed-methylated samples for $240 \mathrm{~min}$. Samples were then acetylated with acetic anhydride at $121^{\circ} \mathrm{C}$ for $180 \mathrm{~min}$. Gas chromatography-mass spectrometry (GC-MS, Agilent Tech- 
nologies) was used to analyze the resulting partially methylated alditol acetates (PMAAs). Glycosidic linkages in the polysaccharide fraction were counted based on the method described by Lee $e t$ al. (2018).

\section{Morphological and mineralogical analyses}

Pre-synthesized uranium phosphate minerals were collected after $24 \mathrm{~h}$ for morphological and mineralogical analyses. The fungal biomass and EPSs were collected after reacting with presynthesized uranium phosphate minerals for $12 \mathrm{~h}$. The samples collected were centrifuged at $10,000 \times g$ for $10 \mathrm{~min}$, and then washed three times with sterile distilled water using centrifugation.

Washed samples were analyzed using scanning electron microscopy (SEM, SU-70; Hitachi), transmission electron microscopy (TEM, Tecnai G2 F30 S-Twin; Field Electron and Ion Company), atomic force microscopy (AFM, XE-100; Park Systems), and Xray diffraction (XRD, D8 advance; Bruker). In SEM and AFM analyses, $5-10 \mu \mathrm{L}$ of samples were placed on silicon wafers and air-dried. In TEM analyses, samples were mounted on copper grids and subsequently air-dried. Energy dispersive X-ray spectroscopy (EDX) was used with SEM and TEM analyses, and selected area electron diffraction (SAED) was equipped at TEM. XRD analyses were performed with fine powder samples. In cross-sectional TEM analyses, washed cells were fixed with $3 \%(\mathrm{v} / \mathrm{v})$ glutaraldehyde for $2 \mathrm{~h}$ and $1 \%$ osmium tetroxide $\left(\mathrm{OsO}_{4}\right)$ at $4^{\circ} \mathrm{C}$ for $3 \mathrm{~h}$ and then dropped onto mesh copper grids covered with carbon film. Cross-sectioned specimens were prepared using a microtome (CR-X; RMC Products). Images were obtained at $200 \mathrm{kV}$ using JEOL JEM-2100 high resolution TEM (JEOL). In morphological analyses of uranium phosphate precipitates after biomineralization experiments, fungal biomasses were collected after 1, 2, 3, and 4 weeks, and the samples collected were prepared as described above.

\section{Analytical methods}

ICP-MS (1100 \& 7500ce; Agilent Technologies) was used to quantify uranium. One milliliter of samples was filtered through a $0.22-\mu \mathrm{m}$ syringe filter (Whatman), and diluted using high-purity $2 \%(\mathrm{v} / \mathrm{v}) \mathrm{HNO}_{3}$.

\section{Results and Discussion}

\section{Identification of the isolated fungus}

In fungal biomineralization experiments performed using the newly isolated fungus strain F1, SEM images showed the precipitation of minerals on the hyphae of the fungus, which was different from A. niger VKMF-1119 (Fig. S1). EDX revealed that the minerals that precipitated on fungal hyphae were made of uranium and phosphate. Based on these results, we assumed that an enzyme phosphatase catalyzed the release of phosphate from glycerophosphate added to the solution, which then reacted with uranium to form uranium phosphate minerals. The activity of acid phosphatase, which was excreted into the fungal agar medium, was confirmed by a color reaction (Matos et al., 2017). In addition, the isolated fungal strain was phylogenetically identified as the genus Cladosporium (Fig. S2), named Cladosporium sp. strain F1 with the accession number MT271897 of the ITS sequence.

\section{Characterization of pre-synthesized uranium phosphate minerals}

SEM images showed that the nanoplate shapes of uranium phosphate minerals were mostly detected at $\mathrm{pH} 4$ to 8 (Fig. 1A). In addition, as $\mathrm{pH}$ decreased from 7 to 4, nanorod-shaped minerals increased. SEM images also showed that as $\mathrm{pH}$ increased from 6 to 8 , octagonalshaped uranium phosphate nanoplates gradually changed to tetragonal-shaped nanoplates. The length of each uranium phosphate nanoplate synthesized at $\mathrm{pH} 6,7$, and 8 ranged from $3-4,1-2$, and $0.5-1 \mu \mathrm{m}$, respectively. TEMSAED pattern analyses showed distinct electron diffraction patterns with the high crystallinity of nanoplates for uranium phosphate nanoplates synthesized at $\mathrm{pH} 6,7$, and 8 (Fig. 1B). The two diffractions angled $45^{\circ}$ had interpla-
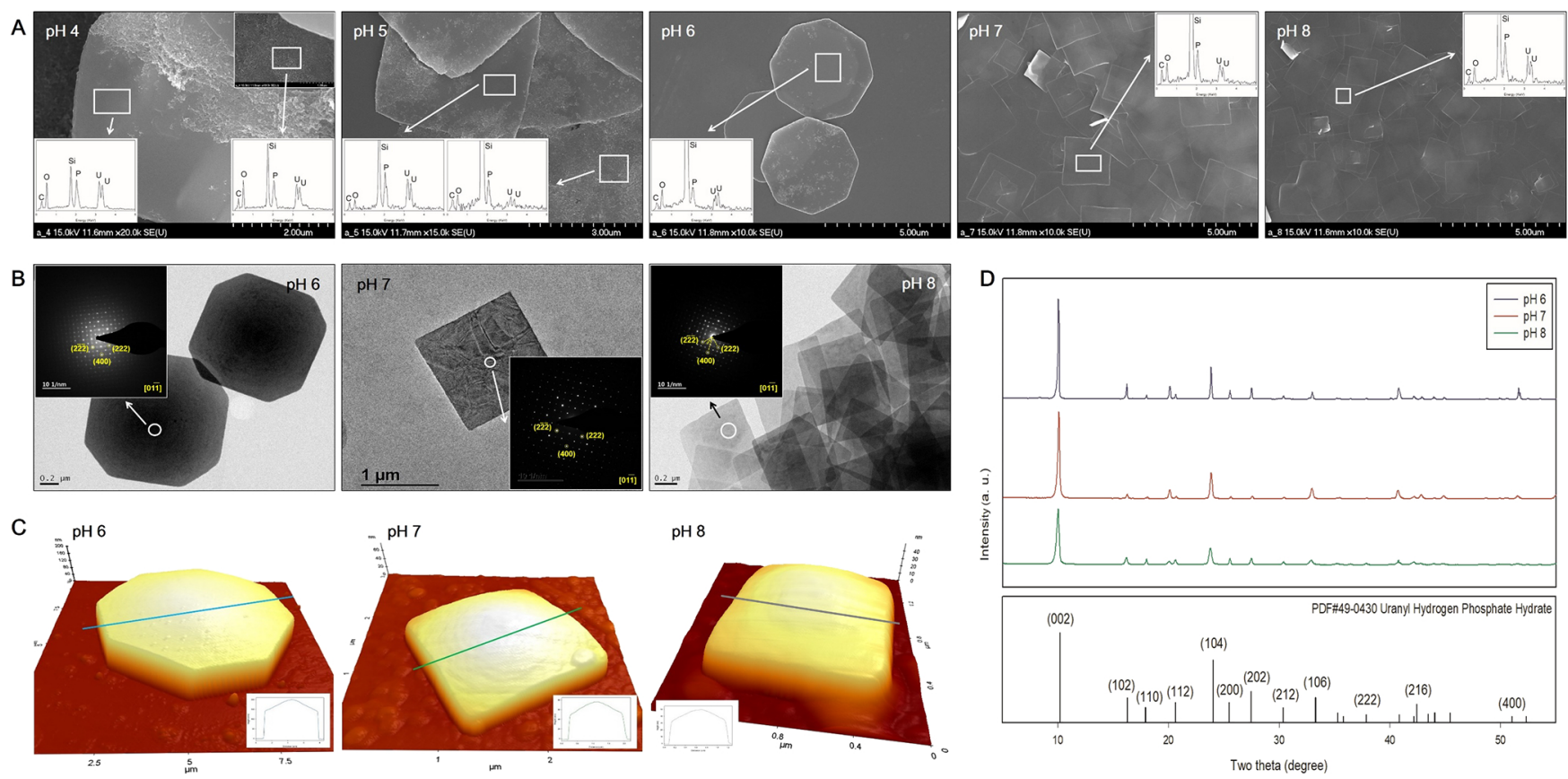

Fig. 1. SEM images of uranium phosphate minerals synthesized from $\mathrm{pH} 4$ to 8 with EDX results (A, inset), TEM images with SAED patterns (B, inset), AFM images with thickness profiles (C, inset), and XRD results (D) of uranium phosphate nanoplates synthesized from pH 6 to 8. 
nar distance values of 2.374 and $1.746 \AA$ respectively, which were indexed as the crystal planes of (222) and (400) of the p4/ncc structure (inset, Fig. 1B). The crystallinity of the materials was confirmed by XRD patterns in the high angle region (Fig. 1D). A series of peaks were detected at $2 \theta=10.192^{\circ}, 16.287^{\circ}, 17.938^{\circ}, 20.634^{\circ}, 24.032^{\circ}$, $25.480^{\circ}, 27.481^{\circ}, 30.378^{\circ}, 33.305^{\circ}, 37.867^{\circ}, 42.423^{\circ}$, and $52.358^{\circ}$ for the samples prepared at $\mathrm{pH} 6,7$, and 8 , which corresponded to reflections by (002), (102), (110), (112), (104), (200), (202), (212), (106), (222), (216), and (400) planes, respectively. This result is consistent with SAED patterns. Therefore, we assumed that the precipitated ura- nium phosphate mineral was uranyl hydrogen phosphate hydrate $\left(\mathrm{HPUO}_{6} \cdot 4 \mathrm{H}_{2} \mathrm{O}\right)$, which matched the reference patterns with PDF\#49-0430 from Powder Diffraction Files.

AFM analyses showed that the central point of each nanoplate was the thickest and thickness gradually decreased towards the edge of the mineral under all $\mathrm{pH}$ conditions (inset) (Fig. 1C). As $\mathrm{pH}$ increased from 6 to 8, the height of each nanoplate at the center point decreased from approximately 203 to $50 \mathrm{~nm}$. Although it was not possible to explain the dependence of the precipitation of different shapes of uranium phosphate minerals on different $\mathrm{pH}$ conditions in the present study, it may be attributed to a change

Cladosporium sp. strain F1

\section{Aspergillus nigerVKMF-1119}

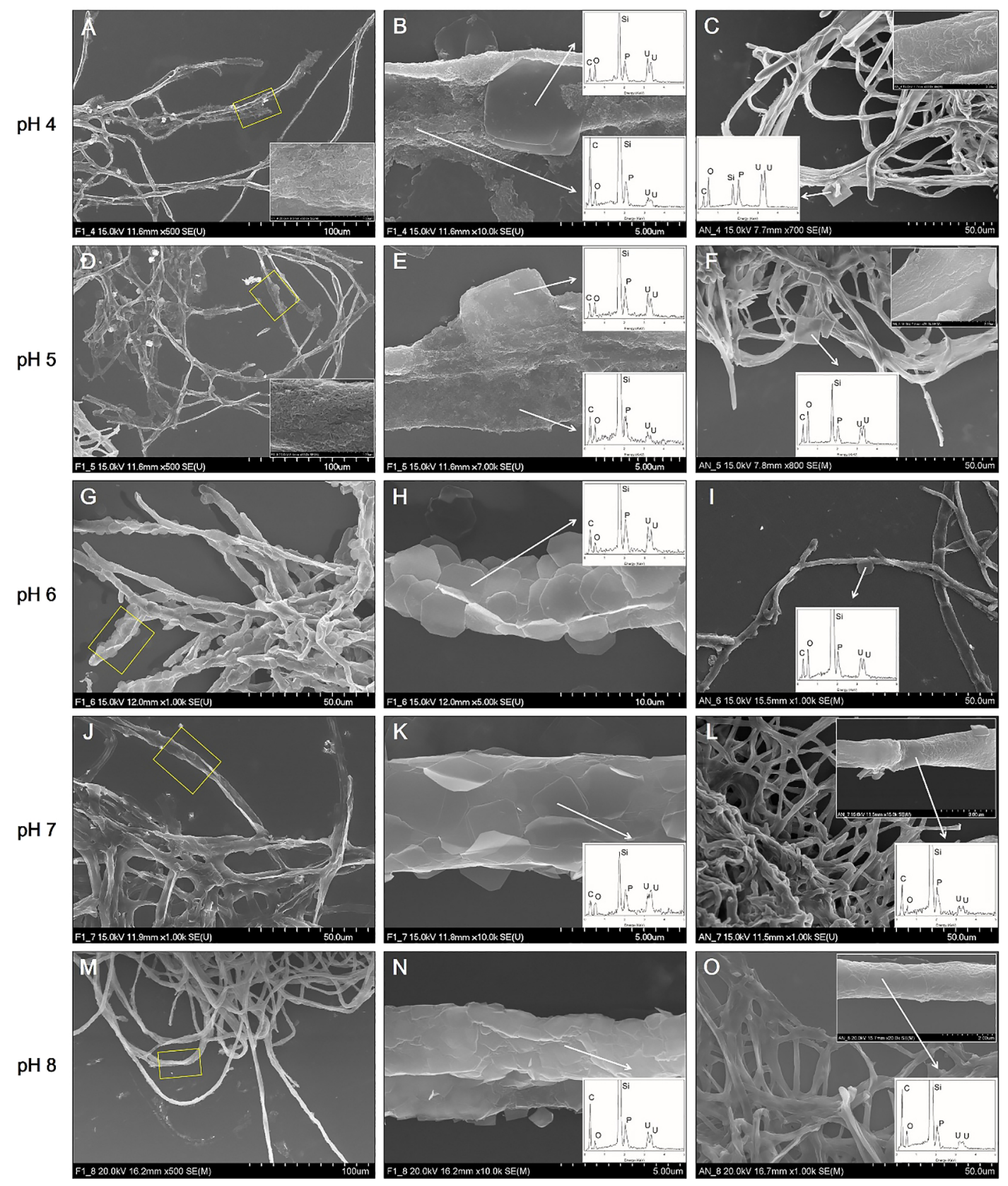

Fig. 2. SEM images of uranium phosphate nanoplates adsorbed on hyphae of Cladosporium sp. strain F1 at pH 4 (A and B), 5 (D and E), 6 (G and $\mathrm{H}), 7(\mathrm{~J}$ and $\mathrm{K})$, and $8(\mathrm{M}$ and $\mathrm{N})$, and on hyphae of Aspergillus niger VKMF-1119 at pH $4(\mathrm{C}), 5(\mathrm{~F}), 6(\mathrm{I}), 7$ (L), and 8 (O) with EDX results (inset). The adsorbed uranium phosphate nanorods were also shown at $\mathrm{pH} 4$ (inset at $\mathrm{A}$ and $\mathrm{C}$ ) and 5 (inset at $\mathrm{D}$ and $\mathrm{F}$ ). 
in the predominant aqueous uranium species under different pH conditions (Suzuki and Banfield, 1999).

Adsorption of pre-synthesized uranium phosphate minerals to Cladosporium sp. strain F1 and A. niger VKMF-1119

Cladosporium sp. strain F1 and A. niger VKMF-1119 showed different patterns for adsorbing uranium phosphate minerals on their hyphae under the applied $\mathrm{pH}$ conditions (Fig. 2). At pH 4 and 5, Cladosporium sp. strain F1 hyphae were extensively encrusted with the nanorods and nanoplates of uranium phosphate minerals, while the adsorption of uranium phosphate minerals on A. niger VKMF-1119 was limited to a few nanoplates (Fig. 2A, B, C, D, E, and F). In addition, Cladosporium sp. strain F1 hyphae were encrusted with multiple layers of uranium phosphate nano-

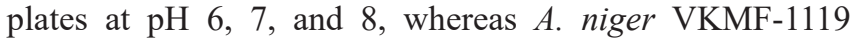
hyphae only adsorbed a few uranium phosphate nanoplates (Fig. 2G, H, I, J, K, L, M, N, and O). While the uranium phosphate nanoplates synthesized at $\mathrm{pH} 6$ were adsorbed on the hyphae of Cladosporium sp. strain F1 with a rigid structure, nanoplates at $\mathrm{pH} 7$ and 8 were bent and adsorbed along fungal hyphae with multiple layers. This may be explained by the size and thickness of each uranium phosphate nanoplate under the applied $\mathrm{pH}$ conditions. Therefore, the small and thin nanoplates that formed at $\mathrm{pH} 7$ and 8 may lead to the extensive adsorption of uranium phosphate minerals to fungal hyphae.

To quantify the uranium phosphate minerals adsorbed on the hyphae of two fungal strains, solubilized uranyl ions from the uranium phosphate minerals remaining in medium were assessed by ICP-MS after filtering and acid treatments (Fig. 3). Although uranium concentrations decreased for Cladosporium sp. strain $\mathrm{F} 1$ and A. niger VKMF-1119, the amount of adsorbed uranium phosphate minerals markedly differed. Cladosporium sp. strain F1 adsorbed 93.1, 89.7, $77.5,80.6$, and $99.6 \%$ of uranium phosphate minerals at $\mathrm{pH} 4,5,6,7$, and 8 , respectively, while only $38.8,78.7$, $56.1,40.3$, and $90.7 \%$ of minerals were adsorbed on $A$. niger VKMF-1119. These results quantitatively proved that Cladosporium sp. strain F1 adsorbed uranium phosphate minerals more efficiently than A. niger VKMF-1119, and, hence, represents a better option for the absorbance of uranium phosphate minerals under a wide range of $\mathrm{pH}$ conditions.

The kinetics of fungal biosorption toward uranium phosphate minerals were quantitatively assessed by ICP-MS, and morphologically observed by SEM analyses at $\mathrm{pH} 7$. ICP-MS results demonstrated that the biosorption capacity of Cladosporium sp. strain F1 toward uranium phosphate minerals was superior to that of $A$. niger VKMF-1119 (Fig. 4). Cladosporium sp. strain F1 adsorbed $57.5 \%$ of uranium phosphate minerals within $1 \mathrm{~h}$, whereas $11.1 \%$ of minerals were adsorbed on $A$. niger VKMF-1119. Adsorbed uranium phosphate minerals increased to $63.0,72.8$, and $80.6 \%$ on the hyphae of Cladosporium sp. strain F1 after 3, 6, and $12 \mathrm{~h}$, respectively, and only to $11.7,16.9$, and $40.3 \%$ on $A$. niger VKMF-1119. The amount of uranium phosphate minerals adsorbed on Cladosporium sp. strain F1 at $1 \mathrm{~h}(57.5 \%)$ was markedly higher than that on A. niger VKMF-1119 at $12 \mathrm{~h}(40.3 \%)$. Differences in biosorption capacities were

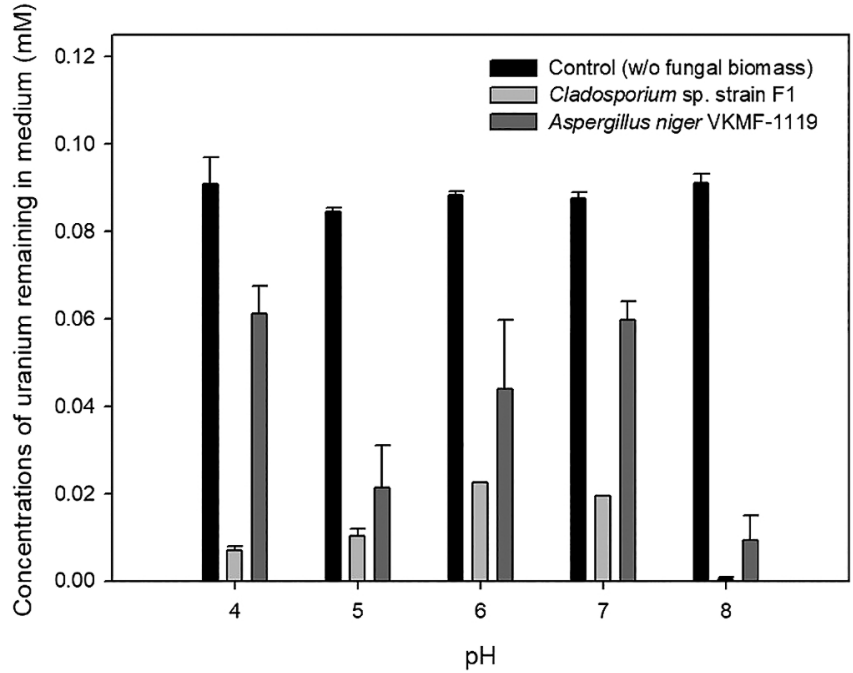

Fig. 3. Amount of uranyl ions remaining in culture medium under different $\mathrm{pH}$ conditions.

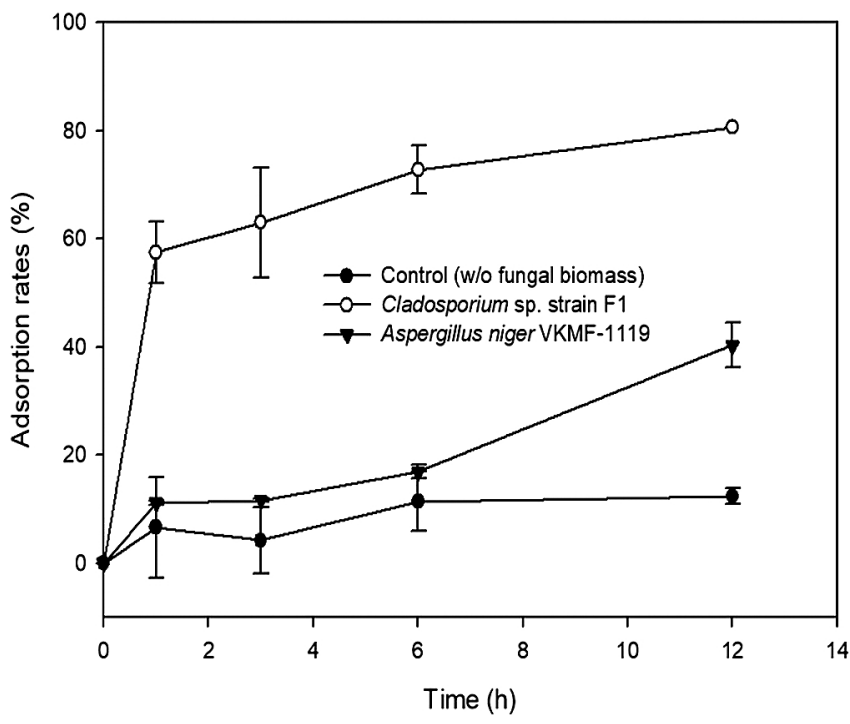

Fig. 4. Adsorption kinetics of uranium phosphate minerals to hyphae of Cladosporium sp. strain F1 and Aspergillus niger VKMF-1119 with time at $\mathrm{pH} 7$.

also morphologically proven by SEM analyses (Fig. 5). Cladosporium sp. strain F1 hyphae were encrusted with uranium phosphate nanoplates at $1 \mathrm{~h}$, whereas difficulties were associated with detecting nanoplates on the hyphae of A. niger VKMF-1119 (Fig. 5A, B, and C), and similar phenomena were observed at $3 \mathrm{~h}$ (Fig. 5D, E, and F) and $6 \mathrm{~h}$ (Fig. 5G, H, and I). Based on kinetic results, Cladosporium sp. strain F1 may be used as an effective adsorbent due to its fast and high biosorption capacity towards uranium phosphate minerals.

To identify the cellular location of uranium phosphate minerals, cross-sectional TEM analyses were performed at $\mathrm{pH}$ 7. The results obtained showed that uranium phosphate minerals did not accumulate inside cells, they were only observed on the cell walls of fungal hyphae (Fig. 6). Therefore, pre-synthesized uranium phosphate minerals did not appear to have the ability to enter fungal cells. Crosssectional TEM images also revealed that Cladosporium sp. 
$1 \mathrm{~h}$
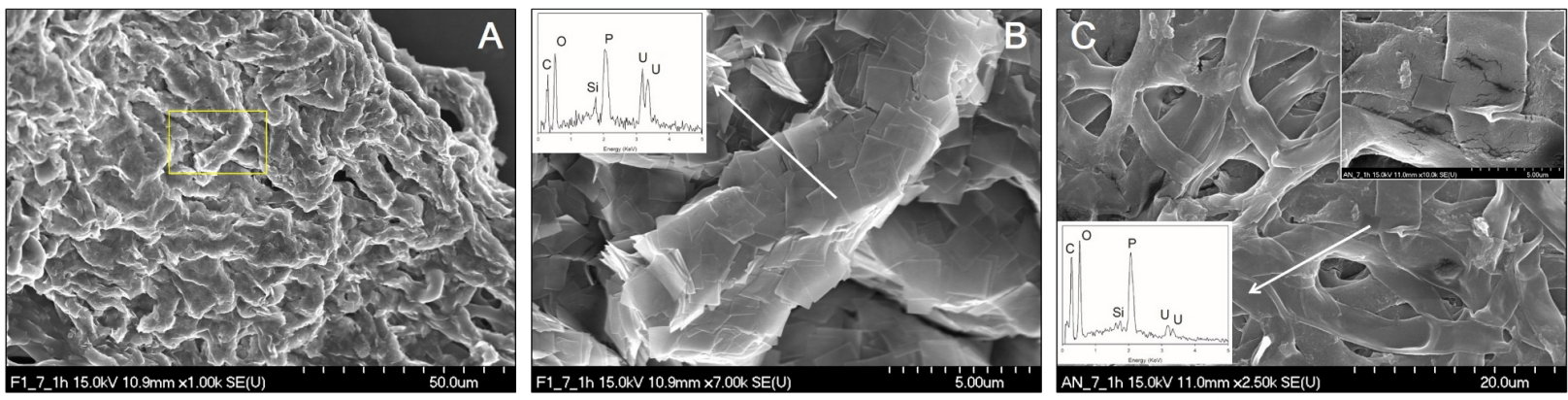

$3 \mathrm{~h}$
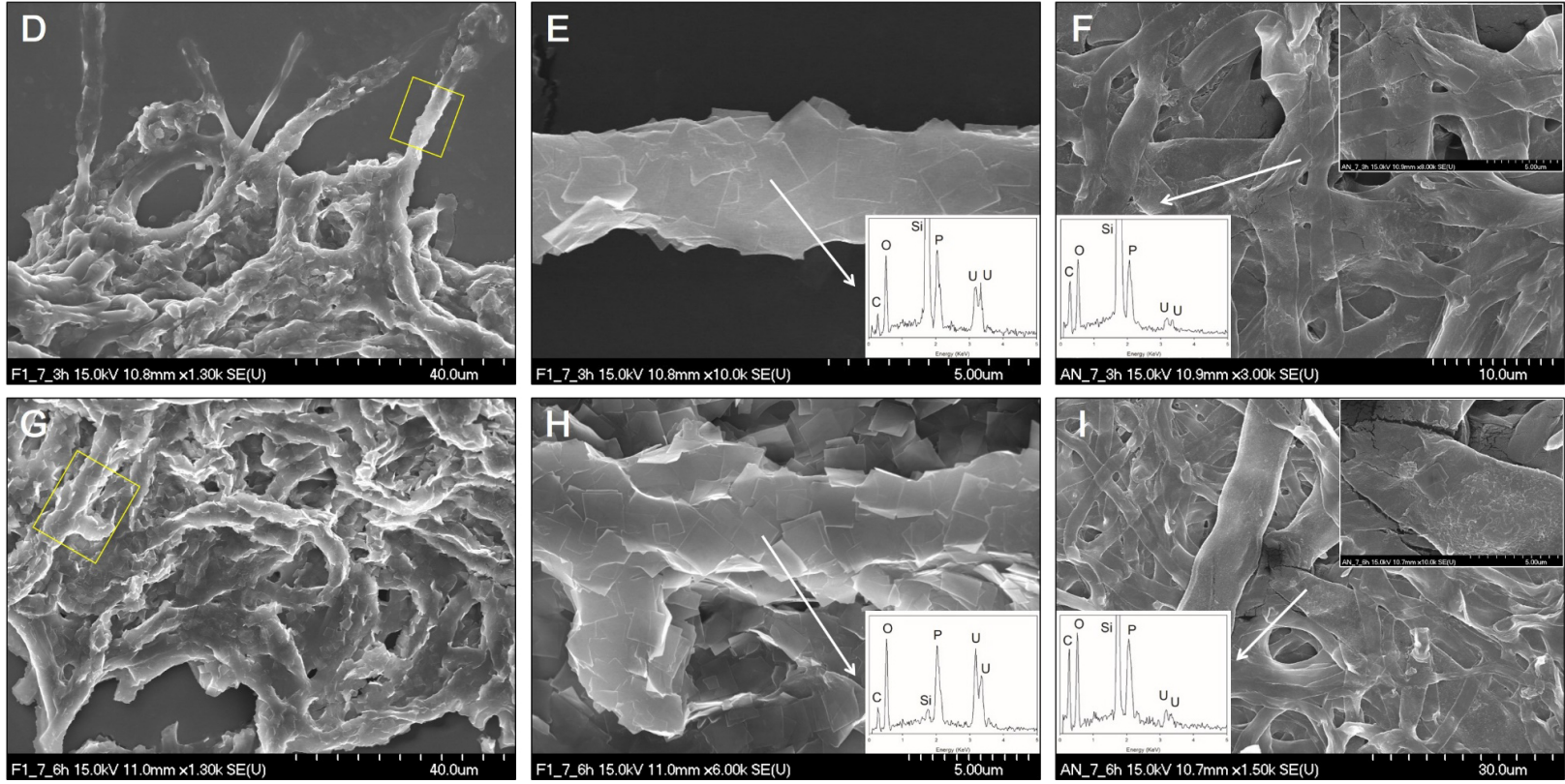

Fig. 5. SEM images of uranium phosphate nanoplates adsorbed on hyphae of Cladosporium sp. strain F1 at $1 \mathrm{~h}(\mathrm{~A}$ and B), $3 \mathrm{~h}$ (D and E), and $6 \mathrm{~h}$ $(\mathrm{G}$ and $\mathrm{H})$, and on hyphae of Aspergillus niger VKMF-1119 at $1 \mathrm{~h}(\mathrm{C}), 3 \mathrm{~h}(\mathrm{~F})$, and $6 \mathrm{~h}(\mathrm{I})$ at $\mathrm{pH} 7$ with EDX results (inset).
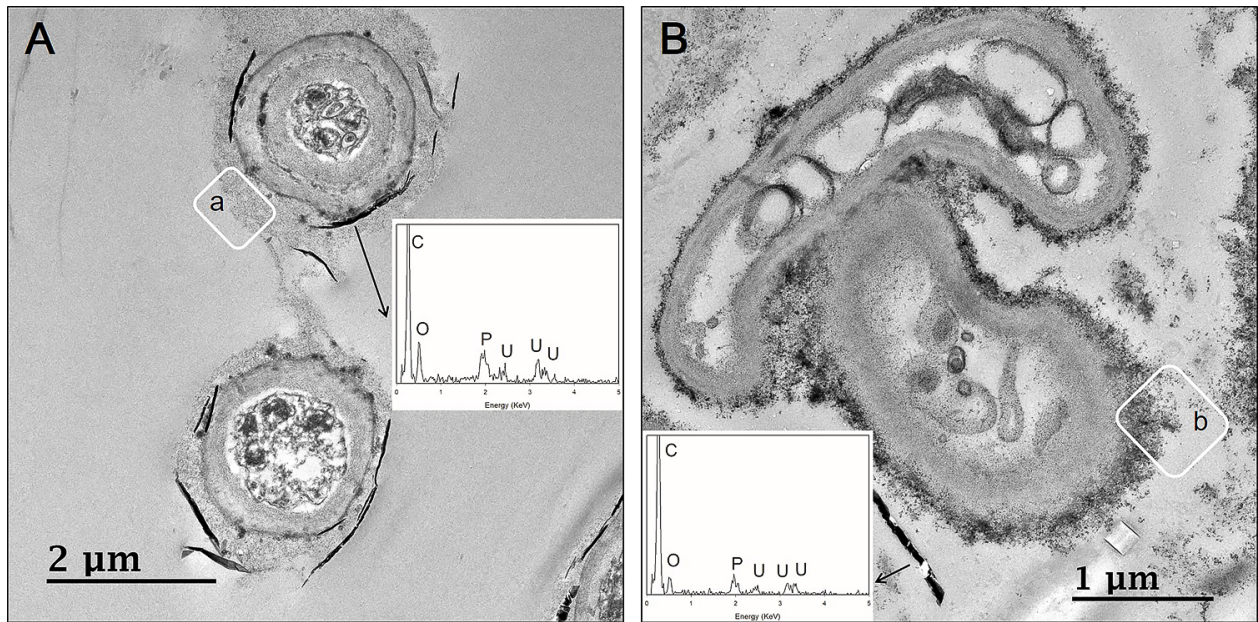

Fig. 6. Cross-sectional TEM images of uranium phosphate nanoplates on hyphae of Cladosporium sp. strain F1 (A) and Aspergillus niger VKMF-1119 (B) at pH 7 with EDX results (inset).

strain F1 hyphae were encrusted by uranium phosphate nanoplates at pH 7 (Fig. 6A), while a few nanoplates were adsorbed on small portions of $A$. niger VKMF-1119 hyphae (Fig. 6B). Therefore, Cladosporium sp. strain F1 appeared to adsorb uranium phosphate minerals more effectively than
A. niger VKMF-1119 at $\mathrm{pH}$ 7. TEM images revealed numerous grey-colored regions between the fungal cell wall and uranium phosphate nanoplates (inset, a and b) (Fig. 6). We assumed that these were fungal EPSs that link the fungal cell wall and uranium phosphate minerals. 
Adsorption of pre-synthesized uranium phosphate minerals to purified EPSs of Cladosporium sp. strain F1 and A. niger $V K M F-1119$

SEM images showed that purified EPSs from Cladosporium sp. strain F1 and A. niger VKMF-1119 after lyophilization were nanosized spheres with diameters of 0.2 to $2 \mu \mathrm{m}$ (Fig. 7A and D). Following the addition of $50 \mathrm{mg}$ of purified fungal EPSs to pre-synthesized uranium phosphate nanoplates in $50 \mathrm{~mL}$ of solution at $\mathrm{pH} 8$, the surfaces of EPSs from Cladosporium sp. strain F1 were compactly encrusted by uranium phosphate nanoplates (Fig. 7B and C), while EPSs from $A$. niger VKMF-1119 adsorbed few nanoplates (Fig. 7E and F). Therefore, fungal EPSs from different sources exhibited different hyphal binding capacities to uranium phosphate minerals possibly due to compositional differences in the structures of the two fungal EPSs.

Characterization of EPSs produced by Cladosporium sp. strain F1 and A. niger VKMF-1119

The MW, sugar compositions, and structures of EPSs were analyzed using HPSEC, HPLC, and methylation analyses. The MW of the two EPSs markedly differed (Fig. 8). The MW of EPSs from Cladosporium sp. strain F1 were 94,900 and 4,400 Da, while those from $A$. niger VKMF-1119 were 75,300, 359, and 193 Da. Overall, Cladosporium sp. strain F1 EPSs were richer in high MW polysaccharides than $A$. niger VKMF-1119 EPSs.

Table 1 shows that the relative amounts of neutral sugar and glucose mole (\%) in EPSs from Cladosporium sp. strain F1 were lower than those from A. niger VKMF-1119. However, mannose and galactose mole (\%) were high in Cladosporium sp. strain F1. The fungal cell wall structure is complex and flexible, being composed of approximately $80 \%$ polysaccharides and small amounts of proteins, lipids, pigments, and inorganic salts (Gow et al., 2017). Therefore, these results also suggest that the two EPSs are polysaccharides with glucan and mannan structures released from fungal cell walls under the culture conditions used.

Table 2 shows the glycosidic linkage conformation of polysaccharides in fungal strains, which was detected by the well-established methylation method for elucidating the structures of polysaccharides. EPSs from Cladosporium sp. strain F1 contained more than sixteen different types of glycosyl linkages, including 4-linked (44.4\%), terminal (13.2\%), 3,4-branched (10.2\%), 4,6-branched $(8.4 \%)$, and 3,4,6-branched (5.6\%) glucopyranosides. However, EPSs from $A$. niger VKMF-1119 contained more than eleven different types of glycosyl linkages, including 4-linked (38.4\%), terminal $(29.0 \%), 4,6$-branched $(10.2 \%)$, 6-linked $(6.3 \%)$, and 3,4-branched (5.5\%) glucopyranosides. Based on these results, both samples appeared to be highly branched glucans; however, the structures of EPSs from Cladosporium sp. strain F1 were larger and more branched than those of $A$. niger VKMF-1119. Further comparative research is needed to identify which component or structure in the fungal EPSs of Cladosporium sp. strain F1 contributes to the better adsorption of uranium phosphate minerals on fungal hyphae.

While previous studies have generally focused on the biosorption of cationic heavy metal species, such as lead, copper, and cadmium ions, onto a number of negatively charged functional groups in the fungal and/or bacterial cell surface, the biosorption of negatively charged heavy metal species, including oxyanions of chromium and arsenic, has not been examined as extensively (Michalak et al., 2013). Uranyl hydrogen phosphate hydrates, which were a close match mineralogically with the pre-synthesized uranium phosphate minerals used in the present study, were shown to be composed of negatively charged layers (Morosin,
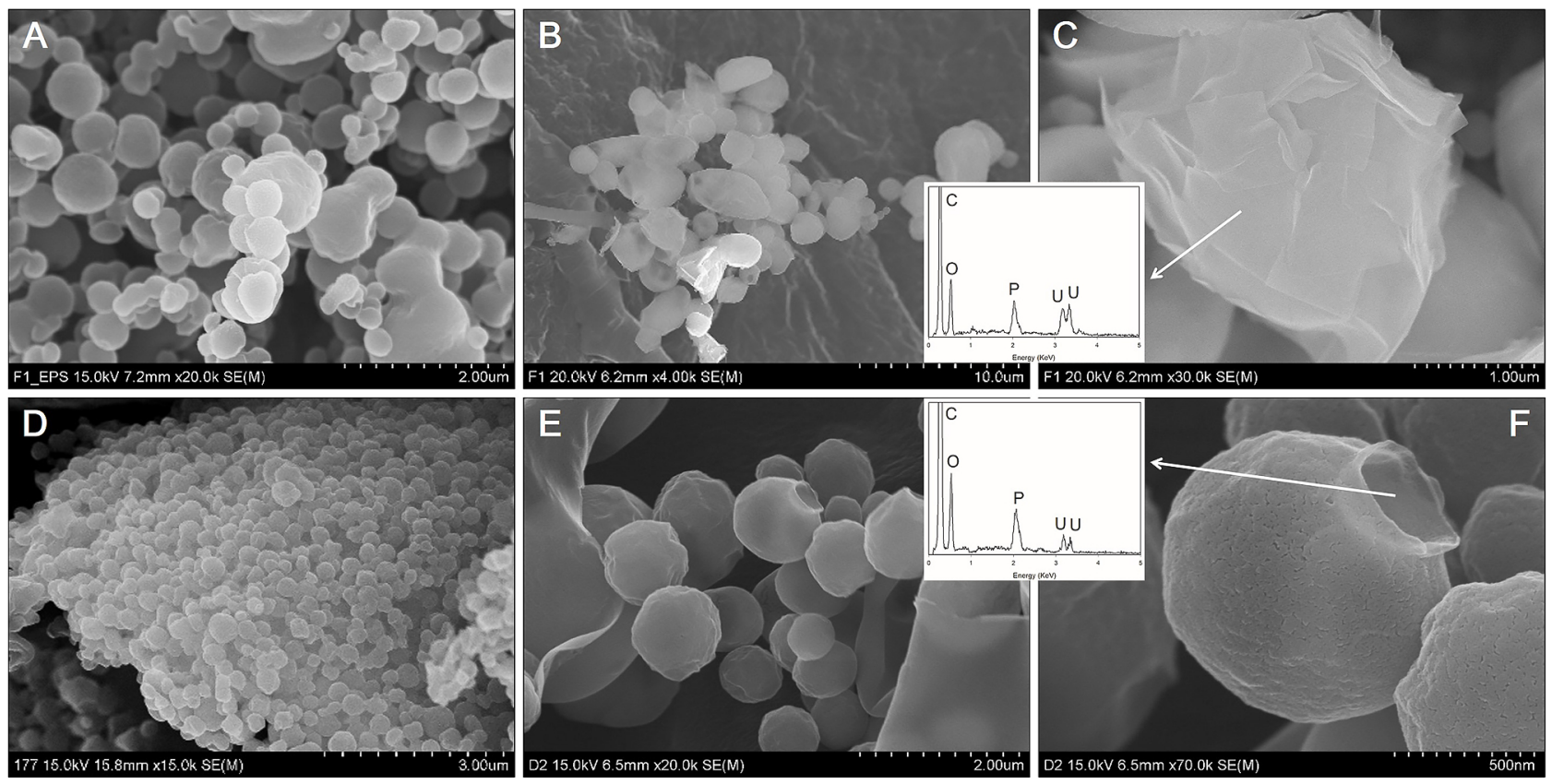

Fig. 7. SEM images of EPSs from Cladosporium sp. strain F1 (A) and Aspergillus niger VKMF-1119 (D), and uranium phosphate nanoplates adsorbed on the surface of EPSs from Cladosporium sp. strain F1 (B and C) and A. niger VKMF-1119 (E and F) at pH 8 with EDX results (inset). 

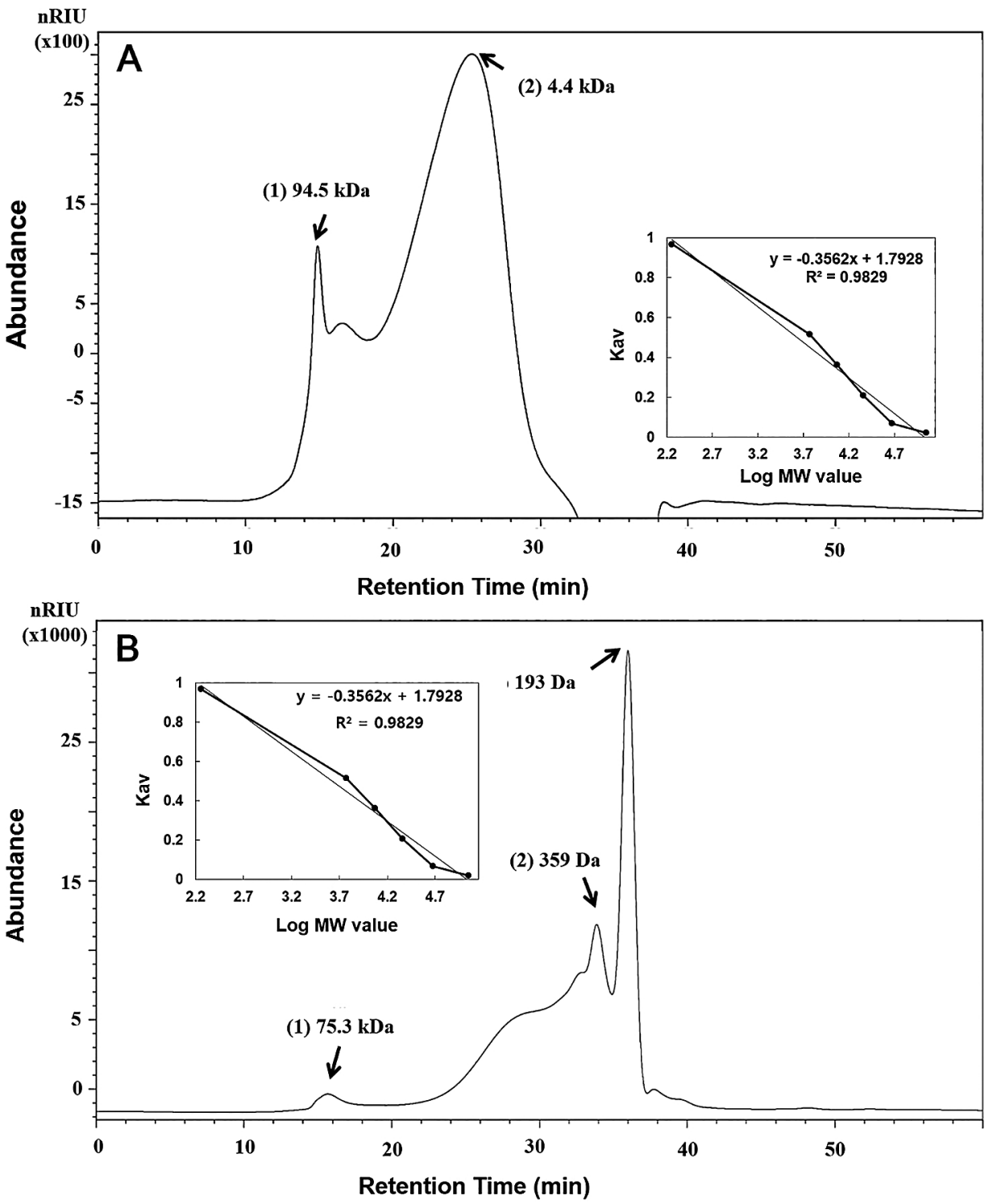

Fig. 8. Molecular weights of EPSs from Cladosporium sp. strain F1 (A) and Aspergillus niger VKMF-1119 (B). The calibration curve equation is $\log \mathrm{MW}=1.7928-0.3562 \mathrm{x}, \mathrm{R}^{2}=0.9829$, where $\mathrm{MW}$ is the molecular weight of the standard dextran and $\mathrm{x}$ is the retention time (inset).

Table 1. Compositional analyses of EPSs from Cladosporium sp. strain F1 and Aspergillus niger VKMF-1119.

\begin{tabular}{llccc}
\hline \multirow{A}{*}{ Polysaccharide component } & $\begin{array}{c}\text { Cladosporium sp. } \\
\text { strain F1 }\end{array}$ & $\begin{array}{c}\text { Aspergillus niger } \\
\text { VKMF-1119 }\end{array}$ & \multirow{2}{*}{$(\%)$} \\
\hline & Neutral sugar & $93.1 \pm 2.1$ & $96.2 \pm 4.3$ & \\
& Uronic acid & $4.8 \pm 0.3$ & $3.4 \pm 0.2$ & \\
Protein & $2.1 \pm 0.5$ & $0.4 \pm 0.4$ & \\
\hline B & Neutral sugar & & & (Mole\%) \\
\hline & Mannose & $6.9 \pm 0.2$ & $3.6 \pm 0.2$ & \\
& Glucose & $88.1 \pm 0.7$ & $96.4 \pm 0.2$ & \\
Galactose & $5.0 \pm 0.5$ & - & \\
\hline
\end{tabular}

1978; Pozas-Tormo et al., 1986; Tu et al., 2019). Differences in the adsorption capacity of the two fungi to the negatively charged layers of pre-synthesized uranyl hydrogen phosphate hydrates may be explained by the total interaction energy, which is calculated by the repulsive electrostatic force and attractive van der Waals force (Pajerski et al., 2019). These physicochemical parameters are attributed to the different physical and chemical structures of the cell wall and different amounts of extruded EPSs, which also offer many different functional groups, such as carboxyl, hydroxyl, sulphate, phosphate, and amino groups in varying degrees (Yin et al., 2011; Chen et al., 2013; Li et al., 2020). Therefore, as shown in Table 1 and 2, the purified EPSs of Cladosporium sp. strain F1 and A. niger VKMF-1119 had 
Table 2. Structural analyses of EPSs from Cladosporium sp. strain F1 and Aspergillus niger VKMF-1119.

\begin{tabular}{|c|c|c|c|}
\hline Fungal strain & Monosaccharide & Glycosidic linkage & Mole $\%$ \\
\hline \multirow{16}{*}{ Cladosporium sp. strain F1 } & \multirow{9}{*}{ Glucose } & Terminal & 13.2 \\
\hline & & $2-$ & 1.0 \\
\hline & & $6-$ & 3.9 \\
\hline & & 4- & 44.4 \\
\hline & & $3,4-$ & 10.2 \\
\hline & & $2,4-$ & 1.9 \\
\hline & & $4,6-$ & 8.4 \\
\hline & & $3,4,6-$ & 5.6 \\
\hline & & $2,4,6-$ & 0.7 \\
\hline & \multirow{4}{*}{ Mannose } & $3-$ & 4.0 \\
\hline & & $2-$ & 1.9 \\
\hline & & $3,6-$ & 0.7 \\
\hline & & $2,6-$ & 0.8 \\
\hline & \multirow{3}{*}{ Galactose } & $3,6-$ & 0.8 \\
\hline & & $4,6-$ & 1.8 \\
\hline & & $2,4,6-$ & 0.7 \\
\hline \multirow{11}{*}{ Aspergillus niger VKMF-1119 } & \multirow{8}{*}{ Glucose } & Terminal & 29.0 \\
\hline & & $2-$ & 1.6 \\
\hline & & $6-$ & 6.3 \\
\hline & & $4-$ & 38.4 \\
\hline & & $3,4-$ & 5.5 \\
\hline & & $2,4-$ & 1.8 \\
\hline & & $4,6-$ & 10.2 \\
\hline & & $3,4,6-$ & 2.2 \\
\hline & \multirow{3}{*}{ Mannose } & 3- & 2.5 \\
\hline & & $2-$ & 1.8 \\
\hline & & $3,6-$ & 0.7 \\
\hline
\end{tabular}

different compositions and structures, which may partially contribute to the differences observed in the total interaction energy, thereby leading to differences in the adsorption of uranyl hydrogen phosphate hydrates. However, we were unable to identify which functional groups or molecules of cell wall components and EPSs were involved in the adsorption of negatively charged minerals. Further comparative genomic and biochemical research is needed to identify the key biological components that contribute to the preferential adsorption of pre-synthesized uranyl hydrogen phosphate hydrates on Cladosporium sp. strain F1.

\section{Conclusions}

The ability of Cladosporium sp. strain F1 to remove uranium phosphate minerals was investigated, and the results obtained revealed unusual structures encrusting fungal hyphae with multiple layers. Regardless of mineral shapes and the $\mathrm{pH}$ conditions applied, the biosorption capacity of Cladosporium sp. strain F1 towards uranium phosphate minerals was superior to that of A. niger VKMF-1119. Based on the physical mobility and chemical stability of uranium phosphate minerals under in situ oxidizing environmental conditions, Cladosporium sp. strain F1 appears to be a better option for collecting and removing uranium from a wide range of $\mathrm{pH}$ conditions where large amounts of phosphate are present in the environment.

\section{Acknowledgements}

This work was supported by the National Research Foundation of Korea (NRF) grant funded by the Korea government (MSIP) (NRF-2016R1A2B3013974). SEM and TEM analyses of morphologies were performed at the Korea Basic Science Institute (KBSI) Gwangju center.

\section{References}

Abdelouas, A., Lu, Y., Lutze, W., and Nuttall, H.E. (1999) Oxidative dissolution of uraninite precipitated on Navago sandstone. J Contam Hydrol 36: 353-375.

Anderson, R.F. (1984) A method for determining the oxidation state of uranium in natural waters. Nucl Instrum Methods Phys Res 223: 213-217.

Arzuaga, X., Rieth, S.H., Bathija, A., and Cooper, G.S. (2010) Renal effects of exposure to natural and depleted uranium: A review of the epidemiologic and experimental data. $J$ Toxicol Environ Health, Part B 13: $527-545$.

Baker, M.R., Coutelot, F.M., and Seaman, J.C. (2019) Phosphate amendments for chemical immobilization of uranium in contaminated soil. Environ Int 129: 565-572.

Banfield, J.F., and Eggleton, R.A. (1989) Apatite replacement and rare earth mobilization, fractionation, and fixation during weathering. Clays Clay Miner 37: 113-127.

Blumenkrantz, N., and Asboe-Hansen, G. (1973) New method for quantitative determination of uronic acids. Anal Biochem 54: 484-489.

Bradford, M.M. (1976) A rapid and sensitive method for the quantitation of microgram quantities of protein utilizing the principle of proteindye binding. Anal Biochem 72: 248-254.

Braun, J.J., Viers, J., Dupré, B., Polve, M., Ndam, J., and Muller, J.P. (1998) Solid/Liquid REE fractionation in the lateritic system of Goyoum, east Cameroon: The implication for the present dynamics of the soil covers of the humid tropical regions. Geochim Cosmochim Acta 62: 273-299. 
Casas, I., Giménez, J., Marti, V., Torrero, M.E., and de Pablo, J. (1994) Kinetic studies of unirradiated $\mathrm{UO}_{2}$ dissolution under oxidizing conditions in batch and flow experiments. Radiochim Acta 66/67: $23-27$.

Chen, Y.P., Zhang, P., Guo, J.S., Fang, F., Gao, X., and Li, C. (2013) Functional groups characteristics of EPS in biofilm growing on different carriers. Chemosphere 92: 633-638.

Dai, J., Wu, Y., Chen, S.W., Zhu, S., Yin, H.P., Wang, M., and Tang, J. (2010) Sugar compositional determination of polysaccharides from Dunaliella salina by modified RP-HPLC method of precolumn derivatization with 1-phenyl-3-methyl-5-pyrazolone. Carbohydr Polym 82: 629-635.

Dhankhar, R., and Hooda, A. (2011) Fungal biosorption - an alternative to meet the challenges of heavy metal pollution in aqueous solutions. Environ Technol 32: 467-491.

Fanizza, M.F., Yoon, H., Zhang, C., Oostrom, M., Wietsma, T.W., Hess, N.J., et al. (2013) Pore-scale evaluation of uranyl phosphate precipitation in a model groundwater system. Water Resour Res 49: 874-890.

Gow, N.A.R., Latge, J.P., and Munro, C.A. (2017) The fungal cell wall: structure, biosynthesis, and function. Microbiol Spectrum 5: doi: 10.1128/microbiolspec.FUNK-0035-2016.

Gu, B., Yan, H., Zhou, P., and Watson, D.B. (2005) Natural humics impact uranium bioreduction and oxidation. Environ Sci Technol 39: $5268-5275$

Gupta, N.K., Sengupta, A., Gupta, A., Sonawane, J.R., and Sahoo, H. (2018) Biosorption-an alternative method for nuclear waste management: a critical review. J Environ Chem Eng 6: 2159-2175.

Hakomori, S.I. (1964) A rapid permethylation of glycolipid, and polysaccharide catalyzed by methylsulfinyl carbanion in dimethyl sulfoxide. J Biochem 55: 205-208.

Hon, Z., Österreicher, J., and Navrátil, L. (2015) Depleted uranium and its effects on humans. Sustainability 7: 4063-4077.

Honda, S., Akao, E., Suzuki, S., Okuda, M., Kakehi, K., and Nakamura, J. (1989) High-performance liquid chromatography of reducing carbohydrates as strongly ultraviolet-absorbing and electrochemically sensitive 1-phenyl-3-methyl-5-pyrazolone derivatives. Anal Biochem 180: 351-357.

Jerden, J.L., Sinha, A.K., and Zelazny, L. (2003) Natural immobilization of uranium by phosphate mineralization in an oxidizing saprolitesoil profile: chemical weathering of the Coles Hill uranium deposit, Virginia. Chem Geol 199: 129-157.

Jerden, J.L., and Sinha, A.K. (2006) Geochemical coupling of uranium and phosphorous in soils overlying an unmined uranium deposit: Coles Hill, Virginia. J Geochem Explor 91: 56-70.

Jiang, S., Kim, M.G., Kim, S.J., Jung, H.S., Lee, S.W., Noh, D.Y., et al. (2011) Bacterial formation of extracellular U(vi) nanowires. Chem Commun (Cambridge, U K) 47: 8076-8078.

Jiang, S., and Hur, H.G. (2013) Effects of the anaerobic respiration of Shewanella oneidensis MR-1 on the stability of extracellular U(VI) nanofibers. Microbes Environ 28: 312-315.

Kanematsu, M., Perdrial, N., Um, W., Chorover, J., and O'Day, P.A (2014) Influence of phosphate and silica on U(VI) precipitation from acidic and neutralized wastewaters. Environ Sci Technol 48: 6097-6106.

Karkhanis, Y.D., Zeltner, J.Y., Jackson, J.J., and Carlo, D.J. (1978) A new and improved microassay to determine 2-keto-3-deoxyoctonate in lipopolysaccharide of Gram-negative bacteria. Anal Biochem 85: 595-601.

Kumar, S., Stecher, G., and Tamura, K. (2016) MEGA7: Molecular evolutionary genetics analysis version 7.0 for bigger datasets. Mol Biol Evol 33: 1870-1874.

Lee, E.H., Park, H.R., Shin, M.S., Cho, S.Y., Choi, H.J., and Shin, K.S. (2014) Antitumor metastasis activity of pectic polysaccharide purified from the peels of Korean Citrus Hallabong. Carbohydr Polym 111: 72-79.

Lee, J.H., and Hur, H.G. (2014) Intracellular uranium accumulation by Shewanella sp. HN-41 under the thiosulfate-reducing condition. $J$ Korean Soc Appl Biol Chem (Korean Ed) 57: 117-121.

Lee, S.J., Lee, H.S., Kim, S.Y., and Shin, K.S. (2018) Immunostimulatory and anti-metastatic activity of polysaccharides isolated from byproducts of the corn starch industry. Carbohydr Polym 181: 911-917.
Li, J., and Zhang, Y. (2012) Remediation technology for the uranium contaminated environment: a review. Procedia Environ Sci 13: 1609-1615.

Li, N., Liu, J., Yang, R., and Wu, L. (2020) Distribution, characteristics of extracellular polymeric substances of Phanerochaete chrysosporium under lead ion stress and the influence on $\mathrm{Pb}$ removal. Sci Rep 10: 17633.

Liu, F., Du, K.J., Fang, Z., You, Y., Wen, G.B., and Lin, Y.W. (2015) Chemical and biological insights into uranium-induced apoptosis of rat hepatic cell line. Radiat Environ Biophys 54: 207-216.

Matos, A.D.M., Gomes, I.C.P., Nietsche, S., Xavier, A.A., Gomes, W.S., Neto, J.A.D.S., and Pereira, M.C.T. (2017) Phosphate solubilization by endophytic bacteria isolated from banana trees. An Acad Bras Cienc 89: 2945-2954.

Mehta, V.S., Maillot, F., Wang, Z., Catalano, J.G., and Giammar, D.E. (2013) Effect of co-solutes on the products and solubility of uranium(VI) precipitated with phosphate. Chem Geol 364: 66-75.

Michalak, I., Chojnacka, K., and Witek-Krowiak, A. (2013) State of the art for the biosorption process-a Review. Appl Biochem Biotechnol 170: $1389-1416$.

Moon, H.S., Komlos, J., and Jaffé, P.R. (2009) Biogenic U(IV) oxidation by dissolved oxygen and nitrate in sediment after prolonged U(VI)/ $\mathrm{Fe}(\mathrm{III}) / \mathrm{SO}(4)(2-)$ reduction. J Contam Hydrol 105: 18-27.

Morosin, B. (1978) Hydrogen uranyl phosphate tetrahydrate, a hydrogen ion solid electrolyte. Acta Crystallogr, Sect B: Struct Sci, Cryst Eng Mater 34: 3732-3734.

Munasinghe, P.S., Elwood Madden, M.E., Brooks, S.C., and Elwood Madden, A.S. (2015) Dynamic interplay between uranyl phosphate precipitation, sorption, and phase evolution. Appl Geochem 58: 147-160.

Murakami, T., Ohnuki, T., Isobe, H., and Sato, T. (1997) Mobility of uranium during weathering. Am Mineral 82: 888-899.

Murakami, T., Sato, T., Ohnuki, T., and Isobe, H. (2005) Field evidence for uranium nanocrystallization and its implications for uranium transport. Chem Geol 221: 117-126.

Pajerski, W., Ochonska, D., Brzychczy-Wolch, M., Indyka, P., Jarosz, M., Golda-Cepa, M., et al. (2019) Attachment efficiency of gold nanoparticles by Gram-positive and Gram-negative bacterial strains governed by surface charges. J Nanopart Res 21: 1-12.

Parth, D.B., Deepesh, P., and Balasubramanian, K. (2014) A review of potential remediation techniques for uranium(VI) ion retrieval from contaminated aqueous environment. J Environ Chem Eng 2: $1621-1634$.

Pettolino, F.A., Walsh, C., Fincher, G.B., and Bacic, A. (2012) Determining the polysaccharide composition of plant cell walls. Nat Protoc 7: 1590.

Pozas-Tormo, R., Moreno-Real, L., Martínez-Lara, M., and BruqueGamez, S. (1986) Layered metal uranyl phosphates. Retention of divalent ions by amine intercalates of uranyl phosphates. Can J Chem 64: 30-34.

Rump, A., Eder, S., Lamkowski, A., Hermann, C., Abend, M., and Port, M. (2019) A quantitative comparison of the chemo- and radiotoxicity of uranium at different enrichment grades. Toxicol Lett 313: $159-168$.

Suzuki, Y., and Banfield, J.F. (1999) Geomicrobiology of uranium. Rev Mineral Geochem 38: 393-432.

Taunton, A.E., Welch, S.A., and Banfield, J.F. (2000) Microbial controls on phosphate and lanthanide distributions during granite weathering and soil formation. Chem Geol 169: 371-382.

Tu, H., Yuan, G., Zhao, C., Liu, J., Yang, J., Liao, J., et al. (2019) U-phosphate biomineralization induced by Baciilus sp. dw-2 in the presence of organic acids. Nucl Eng Technol 51: 1322-1332.

Wufuer, R., Wei, Y., Lin, Q., Wang, H., Song, W., Liu, W., et al. (2017) Chapter four-uranium bioreduction and biomineralization. Adv Appl Microbiol 101: 137-168.

Yin, Y., Hu, Y., and Xiong, F. (2011) Sorption of $\mathrm{Cu}(\mathrm{II})$ and $\mathrm{Cd}(\mathrm{II})$ by extracellular polymeric substances (EPS) from Aspergillus fumigatus. Int Biodeterior Biodegrad 65: 1012-1018.

Zhong, L., Liu, C., Zachara, J.M., Kennedy, D.W., Szecsody, J.E., and Wood, B. (2005) Oxidative remobilization of biogenic uranium(IV) precipitates: Effect of iron(II) and pH. J Environ Qual 34: 1763-1771.

Zhou, P., and Gu, B.H. (2005) Extraction of oxidized and reduced forms of uranium from contaminated soils: effects of carbonate concentration and pH. Environ Sci Technol 39: 4435-4440. 